\title{
The Attitudes of Fifth and Sixth Graders in Kuwait Governmental Schools towards Recreational and Academic Reading in English
}

\author{
Amel M. Al-Adwani ${ }^{1} \&$ Anaam Al-Fadley ${ }^{2}$ \\ ${ }^{1}$ English language Department, College of Basic Education. PAEET, Kuwait \\ ${ }^{2}$ Curriculum \& Instructions Department, College of Basic Education, PAAET, Kuwait \\ Corresponding: Amel M. Al-Adwani, College of Basic Education, English Dept. PAEET, Kuwait. P.O. Box. \\ 17972 Khaldyia, Kuwait. E-mail: amelq8@yahoo.com
}

Anaam Al-Fadley, College of Basic Education, Curriculum\& Instructions Department, PAEET, P.O. Box. 666, Aladaan, 47000, Kuwait. E-mail: anamalfadely@yahoo.com

Received: September 20, 2017

Accepted: October 30, 2017 Online Published: November 2, 2017

doi: $10.5539 /$ elt.v10n12p37

URL: http://doi.org/10.5539/elt.v10n12p37

\begin{abstract}
The current study is a quantitative research that examined the mean differences of the students' attitude towards reading, based upon several demographic variables (such as gender, grade level and social media devices usage)

The researchers used the Students' Reading Attitude Survey (SRAS) as the dependent variable; the sample consisted of 812 young elementary students (from the 5th and 6th grade) randomly selected from public schools.

The research findings revealed that Kuwaiti students possess favorable attitudes toward both leisure and academic reading. Girls showed more positive attitudes toward reading than boys did. Younger students from the $5^{\text {th }}$ grade showed more positive attitude toward reading than those of the $6^{\text {th }}$ grade. Nevertheless, the results indicated that having an account in Instagram, Snap chat, or YouTube, or possessing a smart device had a negative effect on attitudes towards reading.

This study is expected to help curriculum designers, education policy makers, and English teachers to promote independent reading amongst school students and enable them to move beyond traditional books by encouraging them to form a community of life-long readers in the Arab world.
\end{abstract}

Keywords: reading, reading attitudes, English as a foreign language EFL, young learners, recreation and academic reading, curriculum, social media, government schools, Kuwait, Arab world

\section{Introduction}

Reading is considered a corner stone for success not just in schools, but throughout one's life (Anderson et al, 1985). As reading helps to develop the mind and personality of a person, it also enriches one's intellectual abilities (N. Shehu \& A. Shehu, 2014). Educators point out that attitude towards reading is critical to determine student's success during the elementary school and first stage of school years (Stanfield, 2008; Miller\& Mecca, 1999). This is so because it plays a significant role in influencing children's regularity of independent reading, their involvement in class reading activities, their choice of reading subjects, and accelerate their academic achievement (Logan \& Johnston, 2009: Mullis et al., 2007; Clark, 2013; Wade, 2012; Cook, 2012). Kuwait's educational system has undergone several major reforms in the recent decades. After the liberation of Kuwait from the Iraqi occupation in 1991, a course combining different grade levels was implemented to help Kuwaitis, both inside and outside Kuwait, to make up for the year lost during the occupation. In 1993, the Kuwait Ministry of Education (KMOE) implemented teaching English as a Foreign Language (EFL) from first grade in government schools (Al-edwani, 2005). Where the Kuwaiti government school's curriculum uses Arabic language as a medium of instruction in all subjects, the student's exposure to the English language is only 45 minutes a day, 5 days a week; the Kuwaiti curriculum for English emphasis on listening and speaking in the primary stage through their secondary stage year. Therefore, many students in Kuwait government schools reach a certain level without the ability to read well in English and their capacity to use multiple thinking skills are usually very low (Al Darwish \& Akbar, 2013).

Furthermore, KMOE implemented another reform in 2006 when a new Minister insisted on using technology in 
the curriculum by distributing I-Pads and flash memory besides academic paper text books in government schools. Such reforms were seen by the current researchers to have impacted student's attitudes toward reading, especially when it came to using smart devices as well as using social media accounts. Literature confirms a lack of reading culture or habitual reading in the Gulf Arab society due to the long existence of oral traditions. (Shannon, 2003) Researchers frequently cite diglossia and late exposure to modern standard Arabic language (MSA) as some of the reasons why Arab children find it difficult to develop reading competence (Fender, 2008).

The study of attitudes towards reading has been the focus of several researchers for decades now (e.g. Askov \& Fischbacb, 1973; Deck \& Barnette, 1976). Moreover, research has shown that frequency of reading is related to positive attitudes towards reading (Baker \& Wigfield, 1999). However, other researchers have found that reading for either recreational or for academic purpose was found to be not positively impacted when readers were found to be using smart devices, like an iPad, iPod, or a smart phone (Ducate \& Lomicka, 2013).

Wang (2000) pinpointed that children's decision to read was based on their attitudes towards reading. He further added, "If children do not like reading or they think reading is boring, their negative attitude toward reading will hinder their reading improvement" (P. 120). Students' unwillingness to read extensively these days is a worrisome phenomenon (Shehu, \& Shehu, 2014). Literature has a contradictory finding about the attitudes of elementary students toward reading. The current study tried to explore the attitudes of elementary students toward reading and the degree to which smart devices and social media impacted reading attitudes.

\section{Literature Review}

\subsection{Attitudes towards Reading}

The study of attitudes and their role in reading extends back for decades (Eccles \& Wigfield, 2002, Mckenna et al., 2012, Deck \& Barnette, 1976). However, a review of the research proves that few studies about the attitudes toward reading have been conducted with students in the elementary stage in an EFL setting in general and the Arab world in particular. A study by Chaudhry (2014) who measured Private English as Secondary Language (ESL) students' attitudes toward e-book usage reported a positive attitude toward reading and comprehension level. Furthermore, Druyor (2012) found in his study that a student who has a positive attitude towards reading tends to have high achievement in reading. Other researchers reported positive attitudes as related to higher achievement in social studies and which leads to sustained lifelong reading (Wade, 2012; Logan \& Jonston, 2009).

Braden (2012) attempted to determine whether students' attitudes towards reading were linked to reading achievement, and whether the presence of reading role models within the classroom could help increase positive attitudes towards reading. Forty-three second graders attending an urban elementary school participated in the six-week intervention. Attitudes towards reading were assessed prior to introduction of the role models and were assessed following the final role model. One role model came to visit the classroom each week, following a standardized protocol involving an introduction, a short talk by the role model, student questions and a reading. The study found that by inviting student-selected positive role models into the classroom to talk about literacy, students would have a more positive attitude towards reading.

Attitude toward reading is defined by Alexander and Filler (1997), as "a system of feelings related toward reading which causes the learner to approach or avoid a reading situation" (p. 934). Smith (1990) defined attitudes toward reading as "a state of mind accompanied by feelings and emotions that make reading more or less probable" (p. 215). McKenna, Kear and Ellsworth (1995) indicated that because of the multiple definitions of attitudes to reading, it might be more accurate to delineate reading attitude into subtypes according to interests: attitude toward recreational reading and attitude toward school-related academic reading, which both have psychological reality. In 1990, McKenna and Kear developed their own instrument for measuring attitudes towards reading for elementary students, grade 1 through grade 6, with separate subscales for measuring both recreational and academic reading.

In a larger study, Kennedy (2006) investigated patterns of achievement motivation and reading behaviors among top- and bottom-achieving fourth grade boys and girls in International Reading Literacy Study (PIRLS) that is an International Standard for reading comprehension, at the fourth grade in 2001 and 2006. Such analyses aim to better understand the characteristics of the top- and bottom-performing boys and girls and their differences in terms of reading habits, their attitudes toward reading, and their reading self-concept. In (PIRLS, 2001) and again in (PIRLS, 2006) girls had higher reading achievement than boys did in nearly all participating countries. Results, including trends for 26 countries, revealed that there were differences between boys and girls in the top and bottom thirds of the achievement distribution. Besides, girls had more positive attitudes towards reading than did boys, and reported talking with others about reading, both at home and at school. This can be valuable 
information for parents and teachers to understand the intricate relationship between gender and reading outcomes.

Black, L, A (2006) studied attitudes to reading across primary stage students in an urban Catholic school in Queensland in Years 1 to 7. Students' developing attitudes to reading and the perceptions of these attitudes held by their teachers were examined. An adapted version of the Elementary Reading Attitude Survey was utilized. Results from the study indicated that older students' attitudes towards recreational reading (in primary school) were not significantly different to younger students' attitudes. Female students however, showed more positive attitudes to recreational reading than male students did. Older students' attitudes towards academic reading were overall more negative, while female students showed significantly more positive attitudes than their male peers. Students' choice of texts varied across the year levels with the most preferred reading materials being chapter books, children's magazines, and comics. These results agreed in one point and disagreed in another with what McKenna, Kear and Ellsworth (1995) found in their study of children's attitudes in US from first grade until sixth grade. This was so because they found that recreational and academic attitudes began relatively at positive point and ended in relative indifference by grade 6 . Besides, they found that girls possessed more positive attitudes than boys at all grade levels towards both academic and recreational reading. A recent study examined the attitudes of Malaysian primary school boys and girls toward reading in English as a Second Language (ESL). Using the Students' Reading Attitude Survey, the findings revealed that the students had positive attitudes toward academic and recreational reading in English as a second language in an ESL setting (Moha-Asraf \& Abdullah, 2016).

Indeed, there are hardly any studies on attitudes toward reading conducted on students who study English as a foreign language. For this study, Attitudes toward Reading are defined as a combination of feelings and behaviors related to a specific learning situation (Stanfileld, 2008).

\subsection{Gender and Attitudes towards Recreational Reading and Academic Reading}

Gender is one of the most important factors that have been studied by many researchers in many countries to investigate its effect on students' attitudes towards reading. This became more pertinent when researchers found that girls performed better than boys in reading (Waston, Kehler, \& Martino, 2010; Stevens, 2011; Schwartz, 2002; Junaid, 2015). In general, most studies reported that females have more positive attitudes towards reading than male students did (Martinz, Aricak, \& Jewell, 2008, Swalandew \& Tube, 2007). Furthermore, Moha-Asraf and Abdulla (2016) examined the attitudes of Malaysian primary school boys and girls towards reading in English as a second language. They found that students had positive attitudes towards academic and recreational reading in English as a second language. However, girls scored significantly higher in all the dimensions of reading attitudes as compared to boys. Other researchers similarly concluded that girls demonstrated more positive attitudes towards reading English as EFL or ESL when compared to boys (Butler, 2007; Gallagher-Brett, 2006; Azlina \& Zaizati, 2011). Interestingly, Abu-Rabia (1995) investigated Canadian Arab eighth-grader immigrants' attitudes towards English as a second language and found that male and female had positive attitudes towards reading in English. However, they differed in terms of the type of attitudes. Male students showed instrumental attitude while female students showed integrative attitude. This result made other researchers factor in the preferences and interests of boys and girls in reading in order to hook both of them to reading which in turn had the potential to impact their academic achievement. This may well help teachers and administrators to draw some important implications for reading policy and practices in schools, while taking into consideration the preferences of each gender. For example, Artola, Sastre, Gratacós and Barraca (2013) replicated a previous investigation conducted in Finland that explored differences in attitudes toward reading in primary schools. In their study, they explored whether these differences in attitudes and interests towards reading increased or decreased in single-sex education schools when compared with coeducation schools. First, they found that there was a difference between boys and girls in terms of interest in reading. Thus, they recommended single sex education, as, according to them "We believe that single sex education might help cater to boys' and girls' natural interests and strengths and therefore facilitate motivation towards reading" (p. 126). They explained that one main reason for the relatively negative attitude of boys towards reading was the fact that boys tended to view reading as being an uncool and effeminate activity.

Griva, Alevriadou and Semoglou (2012) identified the correlation between gender and reading preferences and attitudes of 6th Grade students of primary school in Greece. Byro (2000) determined the relationship between reading attitude and gender to compare reading attitudes between boys and girls regarding both academic and recreational reading. The seventy-nine (79) subjects who participated in this study were taken from the total population of the third and fourth grade classes in a public elementary school in a suburban area in southern New Jersey. The Elementary Reading Attitude Survey (ERAS) (McKenna \& Kear, 1990) was used to assess reading 
attitudes. The results indicated that there were significant differences based on gender in the overall or total scale, and in the academic and recreational subscales. Females outperformed males in their achievement.

The results indicated significant differences in reading preferences between male and female students, since the female students showed a greater preference for 'human-interest' stories and male preferred to read comics and action-stories. Their results agreed with Merisuo-Storm (2006) who found that boys liked mostly comics and humorous books while girls preferred adventure books. Also, Artola, T; Sastre, S; Gratacós, G \& Barraca, J (2013) found that boys preferred non-fiction books, comics, adventures and sports magazine. For boys, reading must not be related to schoolwork. On the other hand, girls enjoyed reading more than boys did and they were more interested in fiction books and books that reflected emotions and feelings.

\subsection{Smart Devices $\mid$ Social Media and Students'Attitudes towards Reading}

Kuwait has witnessed a rapid socioeconomic change since the discovery of oil in the late 1940s (Alqashan, 2017). However, more rapid changes have accrued since the launch of smart devices; such change in life style of Kuwaitis affected not only the lives of adults, but mainly that of the younger generation.

Smart device sand social media have expanded the knowledge of the younger generation and wariness in several aspects of life in general and in education in specific. For example, these handheld technologies (iPad, iPods, smart phones) despite their small size have become attractive and easy for students to use for facilitating socio-cultural opportunities for learning (Pachler, Cook, \& Bradley, 2009). It becomes obvious, that the use of smart devices by young students is now a nearly universal phenomenon (World Bank Report, 2016). Greenfield, (2012) claimed that digital e-books is a more interactive method for reading than children's traditional print books.

Several studies reported a positive relationship between mobile usage and language learning (Horen and Palala, 2011; Baleghizadeh \& Oladrostan, 2010; Comas et al., 2009). In addition, smart devices were linked to faster reading and self-regulated style of learning among students (Kondo, 2012).

Social media has been the corner stone for obtaining smart devices and it has more influence on young generation than any other socio-demographic factors. Social network sites allow students to establish "relationships between many people outside their community, and observe problem solving situations of daily life" (Salinas, 2001). Indeed, since their launch, trendy Apps (such as Facebook, Instagram, Snap chat and Twitter), became instantly popular with the young generation. For example, "Facebook" as an academic network was launched for Harvard students in 2004 (Villafueret \& Romero, 2017) by Mark Zuckerberg and his colleagues. It was followed by "YouTube" App launched in in 2005 by Chad Hurley. In 2006 "Twitter" was a blog project of Evan Williams (creator of Google), but it became a very popular social network in the following years. Later, "Whatsapp" was introduced in 2008 by Gonzalez in 2012 to exchange live pictures as communication process, while Apple stores launched "Instagram". In the same year, "Snapchat" was developed by Evan Spiegel, which became popular after 2012 due to its multiple users. Finally, from 2016 onwards users could make video calls on smartphones and other mobile devices using" Whatsapp" or "Facebook". The lenses for "Selfies" caused attention among "Snapchat" users, reaching 200 million users around the world in 2015. In January 2016it's registered 7.000 million views the videos per day (Vaynerchuck, 2016).

Still, as stated by Kirschner (2015), that students may not know how to use such apps in academic work, because these apps are used mostly for information exchange. Furthermore, Kirschnera affirmed in his study that "there is a long road to travel down before social networking sites like Facebook can be effectively and efficiently used as tool for knowledge construction, and knowledge creation (p. 4).

Loan (2009) summarized the problem that faced educationalists and parents in our modern multi-media society and it is that cell phones, computer and internet have become the "Time Eating Machine", a thing that has made reading take a back seat. No one can deny the importance of mass-media technology in simplifying and modifying our lives. However, as Turkyilmaz (2014) noted that although the main aim of mass media technologies is to make people access information as fast as possible and share it at similar settings, children and teenagers preferred to use them to follow people or play computer games.

The problem got worse when the amount of time that children and teenagers spend on these technologies exceeds the time they spend on more important activities such as reading. Brant (2003) referred to a research done in US in which $37 \%$ of the participants declared that engaging in technological devices translated into lesser time spent on reading. Other researchers have pinpointed particular reading habits that have suffered because of the use of computers by readers and these are: pleasure from reading, decline in reading comprehension, having less time to spare for reading, and poor imagination (Beentjes et al., 2001; Brant, 2003; 
Demirer et al., 2011).

Many other researchers have investigated, in particular, the use of the internet and social networking sites or social media and their impact on the reading attitudes of children and youth. Sahbaz (2012) in his home country, Turkey, investigated the reading attitudes of $8^{\text {th }}$ graders in primary education to see if these differed based on the following three variables: gender, computer use, and internet use. As expected, the difference in gender was more pronounced in case of female students and internet use has a negative effect on children's reading attitudes. Tan and Majid (2008) conducted a study in Singapore and found that $57.6 \%$ of the children in Singapore preferred playing games on the computer or surfing the internet whereas only $44 \%$ preferred reading for pleasure. In Turkey, Turkyilmaz (2014) studied the effect of mass media usages, possessions of smart phones, having social media accounts such as " Facebook" and "'Twitter " and using "internet café" on the attitudes of high school students towards reading. He found that the attitudes of the participants who frequented internet cafés and played digital games were at a significantly lower level than the ones who did not engage in either of these activities. The situation seemed to be worse among college students. Shehu (2014) investigated the effect of social networking on students' attitudes towards reading among undergraduate students in Nigeria, he found that $94.5 \%$ of the participants indicated that their use of social networking was to connect with friends and relatives and $36 \%$ of the participants indicated that social networking distracted their reading habits. The researcher noted that even the time they spent on social networking was worrisome.

\section{Statement of the Problem}

Reading is considered to be the corner-stone for success not just in schools, but also for life (Anderson et al., 1985). Literatures have contradictory findings about the attitudes of elementary students toward reading (Clark, 2013; Wade, 2012; Cook, 2012.).

Unfortunately, literature and accounts of teachers illustrate a lack of habitual reading in the Gulf Arab Society (Sahnnon, 2003). Previous studies revealed that teachers complained about the reading ability of Kuwaiti students (Aledwani, 2005, Al- Darwish \& Akbar, 2013). In this study the researchers decided to have participants from the fifth and sixth grade due to Kuwait Education system, which consider the Fifth grade as the last year in the elementary/ primary level, whereas the sixth grade is consider the first year in the middle school in Kuwait. The current study is an attempt to explore the attitudes of elementary students toward reading and the degree to which other variables, like gender, grade level, possession of smart devices, as well as using social media, impact such attitudes.

\section{Significance of the Study}

Based upon the scanned literature review done by the researchers, no single study has till date explored the attitudes of Kuwaiti students toward reading in the primary / elementary stage. Reading is considered to be one of the four language skills - beside listening, speaking, and writing - and very important in developing language competencies in learning a foreign language. Indeed, a good reading habit is the key for a successful life for a person - not only in the academic life, but in general in life. So, a study of the attitude of young students towards reading (recreational and academic reading) will provide policy makers and educators clear and incisive insights for conceptualizing and implementing future educational reforms.

\section{The Research Questions}

1) Is there a difference between male and female students in terms of their attitudes towards recreational reading in English?

2) Is there a difference between male and female students in terms of their attitudes towards academic reading in English?

3) Do high technological devices affect students' attitudes towards reading in English?

4) Do social media affect students' attitudes towards reading in English?

\section{Methodology}

The current research conducted a quantitative study which examined the mean differences of the students' attitude towards reading based upon certain demographic variables. The researchers used a self-report survey methodology with several statistical tools to examine mean differences (t-test, One way Anova).

\subsection{Variables and Instruments}

\subsubsection{The Students' Reading Attitude Survey (SRAS)}

The researchers used the Students' Reading Attitude Survey (SRAS) as the dependent variable, which was 
adapted from the Elementary Reading Attitude Survey (ERAS) (McKenna \& Kear, 1990; Butler, 2007). It consisted of 20 items formulated in brief and simply worded statements about reading. Each item was followed by four pictures of Garfield in four poses to depict different emotional states (happiest, slightly smiling, mildly upset, very upset), The SRAS had two sub-scales to measure aspects of reading attitudes, "recreational reading" (10 items) and "academic reading" (10 items). The general reading attitude was obtained by summing up the scores of the two sub-scales together.

\subsubsection{Independent Variables}

In addition to the dependent variable ((ERAS), several independent variables were used for the purpose of the current study. These variables were gender, class grade, possession and usage of smart devices (Mobile, I-pad, Play station), and possession of social media accounts (YouTube, Instagram, and Snapchat).

\subsection{Procedures}

Advance arrangements were done with the instructors of each course. The original survey was written in English; however, they were translated into Arabic since that was the subject's native language.

To ensure the validity of this instrument, a panel of professors from the College of Basic Education and Kuwait University reviewed the instruments and endorsed content validity of the items. In addition, the researchers conducted a pilot study prior to the instruments application and modified the questionnaire according to the reviewers and the students' feedback. The ERAS is scored using four point Likert scale. However, during the pilot study, the researchers found that the 4 point Likert scale was confusing for most of the students chosen for the study. For this reason, a 3 point Likert scale was finally implemented (Happy (3), Neutral (2), and Unhappy (1)). The score for the total scale ranged from 20 to 60 as a positive, while, sub-scale (Recreational or Academic) ranged from 10 to 30 .

After formulating the final form of the questionnaire, the researchers with their assistants spent the first 15 minutes to explain to the participants the purpose of the study and the way to choose their answers. Participants were asked not to put their names or any personal information such as phone number or addresses to guarantee and maintain the confidentiality of the participants.

In each class, the teacher was asked to read aloud to the students for each item; after each read item, students were asked to circle or mark the Garfield that most closely represented their attitude about each item.

Our findings suggest that the SRAS survey was a reliable instrument in applications with Kuwaiti elementary students. The scale has high internal consistency, test-retest reliability, and validity when applied on young students. A coefficient alpha was calculated to test the internal consistency or reliability of the scale and the sub-scales. Beard and Turnbo (2005) tested the reliability and the stability of ERAS scores for recreational and academic subscales and the total scale and found an internal consistency across gender, grade level, with all coefficients exceeding .75 .

For the translated scale, the total scale showed excellent reliability with a correlation of 0.92 . While the Alpha for the recreational reading sub-scale was .875 , the Alpha for the academic sub-scale reading was .879 (See Table 2).

Table 1. Descriptive statistics and reliability coefficients of the attitudes toward reading scale

\begin{tabular}{lllll}
\hline Variable & Mean & S.D. & N & Alphas \\
\hline Total Attitudes toward Reading Scale & 38.66 & 10.135 & 812 & .92 \\
Sub-Scale Recreational Reading Scale & 31.94 & 5.65 & 812 & .875 \\
Sub-Scale Academic Reading Scale & 28.3 & 5.32 & 812 & .879 \\
\hline
\end{tabular}

\subsection{Sample}

The samples for the current study consisted of 812 young elementary students (from the 5th and 6th grades) who were chosen randomly from public schools across the six educational districts of Kuwaiti Ministry of Education. Boys were $51.1 \%$ (412) while, girls represent $48.9 \%$ (400) of the total sample. 
Table 2. Sample socio-demographic background

\begin{tabular}{llll}
\hline Variable & Type & Frequencies & $\%$ \\
\hline Gender & Boys & 412 & 51.1 \\
Grade Level & Girls & 400 & 48.9 \\
& 5 th & 421 & 50.7 \\
Have Mobile & th & 400 & 49.3 \\
Have I-pad & Yes & 472 & 58.1 \\
& No & 340 & 41.9 \\
Have Play-station & Yes & 426 & 52.5 \\
& No & 386 & 47.5 \\
Having More than one Device & Yes & 346 & 44.8 \\
& No & 448 & 55.2 \\
Having Instgram account & No Device & 88 & 10.8 \\
& One Device & 339 & 41.7 \\
Having YouTube account & 2 Devices & 232 & 28.6 \\
Having Snapchat account & 3 Devices & 253 & 18.8 \\
& Yes & 371 & 45.7 \\
Number of Social Media Account & No & 441 & 54.3 \\
& Yes & 497 & 61.2 \\
& No & 315 & 38.8 \\
& Yes & 468 & 57.6 \\
& No & 344 & 42.4 \\
& No Account & 151 & 18.6 \\
& One Account & 277 & 34.1 \\
& Two Accounts & 205 & 25.2 \\
\hline
\end{tabular}

Most of the students possessed more than one smart device (89.2\%). Only 10.8\% indicated having no mobile or I-pad or Play station. Indeed, $58.1 \%$ reported having mobile, while $52.2 \%$ indicated having an I-pad, while $44.8 \%$ had a play station device. On the other hand, most of the sample (61.2\%) reported having an account and watching YouTube, while, $57.6 \%$ had shared some material on Snapchat. Instagram was the least popular social media site for the students - only $45.7 \%$ reported using it.

\section{Results}

The research questions of this study were answered using t-test to determine whether gender and grade level influenced the attitudes of young students toward reading, by comparing group means.

Table (3) answered the first three research questions. The findings suggested that there was a significant mean difference per students' gender and grade levels that reflected on their attitudes towards reading. Girls have had more positive attitudes towards reading (40.27) than boys (33.20) in the total attitude scale with a significant $P$ value of (.000). For the mean differences on the attitude towards recreational reading subscale, girls also showed a significant mean difference compared to boys in terms of attitude toward recreational reading. Table (3) demonstrates that the mean recreational attitudes for girls was higher (20.23) than for boys (17.9) with a significant $\mathrm{P}$ value of (.000).

For the mean differences on the attitude towards academic reading subscale, girls also showed a significant mean difference, when compared with boys in terms of attitude toward recreational reading. Table (2) demonstrates that the mean recreational attitudes for girls was higher (20.8) than boys (18.12) with a with a significant $\mathrm{P}$ value of $(.000)$. 
A student's grade level was also found to have an impact on a student's attitude towards reading. Younger students from grade $5^{\text {th }}$ showed more positive attitude towards reading with a mean of (36.82) than those of grade $6^{\text {th }}(33.62)$ with a significant $P$ value of $(000)$.

Table 3. Mean diferences and standard diviation for gender and grade level for the students' attitudes toward reading

\begin{tabular}{llllll}
\hline Variable & Variable & $\mathrm{M}$ & $\mathrm{SD}$ & $\mathrm{T}$ & $\mathrm{p}$ \\
\hline Attitude Toward Reading & Boys & 33.20 & 13.648 & -7.4 & 000 \\
& Girls & 40.27 & 10.341 & & \\
Recreational Reading Sub-scale & Boys & 17.9 & 5.4 & -5.97 & 000 \\
& Girls & 20.23 & 5.5 & & \\
Academic Reading Sub-scale & Boys & 18.12 & 5.6 & -7.3 & 000 \\
& Girls & 20.8 & 4.6 & & \\
Grade Level & 5th Grade & 36.82 & 10.34 & 2.91 & 000 \\
& 6th Grade & 33.62 & 17.32 & & \\
\hline
\end{tabular}

$p .>.05$.

Table 4. Mean diferences and standard diviation for those who have smart phone and their attitudes toward reading

\begin{tabular}{|c|c|c|c|c|c|}
\hline Variable & Device or Account & $\mathrm{M}$ & $\mathrm{SD}$ & $\mathrm{f}$ & $\mathrm{p}$ \\
\hline \multirow[t]{2}{*}{ Attitude Toward Reading } & Have one or more device & 36.51 & 10.88 & 3.87 & 000 \\
\hline & Do not have any device & 39.76 & 9.1 & & \\
\hline \multirow{2}{*}{$\begin{array}{l}\text { Recreational } \\
\text { Sub-scale }\end{array}$} & Have one or more device & 18.58 & 5.86 & 3.03 & 000 \\
\hline & Do not have any device & 19.82 & 5.30 & & \\
\hline \multirow[t]{2}{*}{ Academic Reading Sub-scale } & Have one or more device & 18.79 & 5.76 & 4.92 & 000 \\
\hline & Do not have any device & 20.36 & 4.63 & & \\
\hline
\end{tabular}

$p .>.05$.

One way Anova was used to compare means based upon the impact of having smart devices on the attitude toward reading in general and for the recreational and academic reading in particular. Data in Table 4 showed that having smart devices like mobile or I-pad or even a play station, had a significant mean difference in the general attitude towards reading. Those who had one and more devices had less positive attitude towards reading $(\mathrm{M}=36.51)$ compared with those who reported not having a smart device (39.76), with a with a significant $\mathrm{P}$ value of (.000). This was also the case for both sub-scales. The mean score for students in the recreational reading attitude sub-scale was (19.82) compared with those who had at least one device (19.82) with a significant $\mathrm{P}$ value of (.000). This was also the case for the academic attitude subscale. Those who reported not having any smart device showed a higher mean (20.36) compared with those who had at least one smart device (18.79) with a with a significant $P$ value of (000). 
Table 5. Mean diferences and standard deviation for those who have account in social media and their attitudes toward reading

\begin{tabular}{llllll}
\hline Variable & Device or Account & $\mathrm{M}$ & $\mathrm{SD}$ & $\mathrm{f}$ & $\mathrm{P}$ \\
\hline Attitude Toward Reading & Have account & 35.25 & 12.01 & 3.87 & 000 \\
& Do not have & 36.70 & 14.269 & & \\
Recreational Reading Sub-scale & Have account & 18.84 & 5.56 & 3.03 & 000 \\
& Do not have & 19.84 & 5.60 & & \\
Academic Reading Sub-scale & Have account & 20.44 & 5.49 & \multirow{2}{*}{1.388} & .166 \\
& Do not have & 18.70 & 5.05 & & \\
\hline
\end{tabular}

$p .>.05$.

One way Anova was also used to compare means based upon the impact of having a social media account on the attitude towards reading in general and for the recreational and academic reading in particular. Data in Table 5 showed that when students used social media like Snap chat or YouTube or even Instagram, they demonstrated significant mean differences in the general attitude towards reading and with the recreational attitude subscale, but not in the academic reading attitude subscale. Those who had one and more social media account exhibited less positive attitude towards reading in general $(\mathrm{M}=33.25)$ when compared with those who reported not having social media accounts (36.70), with a significant $P$ value of (.000). This was also the case for recreational reading attitude subscale, where the mean score for students who had no social media account was (19.19.84) compared with those who were found to have at least one account (18.84) with a significant $\mathrm{P}$ value of (.000). However, this case was not supported in terms of the academic attitude sub-scale. Those who reported not having any social media account did not show significant mean differences. However, those who had at least one social media account a showed a higher mean (20.44) when compared with those who had at least one (18.70) with a significant $P$ value of (.166).

\section{Discussion}

One of the main findings was that the study revealed Kuwaiti students carry favorable attitudes towards both leisure and academic reading. This result was not surprising when we compared it with data emerging from other developed countries. For example, researchers have reported a positive shift in attitudes toward reading. Reading and speaking English has gained popularity as English in general is now accepted as a language for development and future progress by Kuwaiti students (Aledwani, 2005). Furthermore, this finding is also supported by a recent study by Moha-Asraf and Abdulla (2016), which examined the attitudes of Malaysian primary school boys and girls towards reading in English as a second language, and found that students had positive attitudes toward recreational and academic reading in English. Other researchers have similarly observed and recorded the positive attitudes towards reading English as EFL or ESL of girls as compared to boys (Butler, 2007; Gallagher-Brett, 2006; Azlina \& Zaizati, 2011).

Another finding reported in the current research is that girls were found to have a more positive attitude toward reading than boys exhibited in the total attitude and both sub-scales. This finding is consistent with other studies, which reported female students to have more positive attitudes toward reading than male students (Martinz, Aricak \& Jewell, 2008, Swalandew \& Tube, 2007). Girls in general have more recreational and academic time compared with boys. Another main reason for a diminished attitude of boys towards reading is that boys viewed reading as uncool and an effeminate activity (Artola et al., 2013). Another justification for gender differences in the attitudes towards reading is discussed by Merisuo-Storm (2006) who insisted that boys mostly liked comics and humorous books while girls preferred adventure books. Gender differences in reading material could be one major factor in such mean differences between boys and girls.

Meanwhile, the grade level of the students was also found to have an impact on students' attitudes toward reading. Younger students from grade 5 th showed more positive attitude towards reading than those of grade $6^{\text {th }}$ did. Our finding is consistent with that of earlier research which found that younger students usually had more positive attitudes as compared to older ones (McKenna, Kear, \& Ellsworth, 1995). Furthermore, they found that recreational and academic attitudes for young students began relatively at a positive point and ended in relative indifference by grade 6 .

However, grade levels cannot be seen as the only and direct factor that influences the students' attitudes. In fact, 
smart devices like mobile or I-pad or even a play-station were found in this study to have a significant impact in the total scale of the attitude towards reading as well as for the sub-scales "recreational and academic reading". An earlier study reported by Turkyilmaz (2014) noted that although the main aim of mass media technologies is to make people access information as fast as possible and share it at similar settings, children and teenagers preferred to use them to follow people or to play computer games.

Furthermore, although technological innovations predicted the "death" of the book since the late nineteenth century (Ehrenreich, 2011), still, the production of books themselves continues to increase year on year. The current study found that in the total and sub-scale scores, amongst the students surveyed, those who had one or more smart device reported less positive attitudes toward reading, when compared with those who reported not having any smart device. This finding is consistent with other findings done by Brant (2003) who referred to a research done in US in which $37 \%$ of the participants declared that engaging with technological devices caused sparing less time in reading. Indeed, similar findings as ours were also reported in a previous study which found that pleasure from reading declined as did reading comprehension, with those who engaged with smart devices, even as they reported have less time to spare for reading, besides exhibiting poor imagination (Beentjes et al., 2001; Brant, 2003; Demirer et al., 2011).

The inferences of our study is also consistent with that of other studies that indicated that most technological developments were not designed while keeping teachers or the classroom in mind. This may of course change with "education friendly" versions but currently its pedagogical use would come via the addictiveness of teachers (Goodwyn, 2011). In fact, parents and teachers as well should be aware that technological devices could be used for improving the attitudes of their kids towards reading. A recent study of third grade readers (Sternberg, Kaplan, and Borck 2007) provides evidence of young children's easy adaption to, and pleasure in, e-readers but with no significant impact on reading comprehension. Educators should train young students early to adapt new smart devices for reading purposes. For example, Larson's studies of elementary classrooms show how rapidly even second graders begin to use the special features of the e-reader, changing font size, using annotation, etc. (Larson, 2009, 2010).

\section{Conclusion and Implications}

To sum up our study in general found favorable attitudes towards both academic and recreational reading prevalent amongst the students. It also indicated that there was a gender dimension to prevailing attitudes, in that girls exhibited more positive attitudes towards reading than did boys. Furthermore, the result revealed that grade level of the students was found to also impact on student attitudes towards reading. Younger students from grade 5 th showed more positive attitude towards reading than did those of grade $6^{\text {th }}$.

In addition, the findings regarding the impact of multi-media on the attitudes toward reading was consistent with findings by Loan (2009), who summarized that in our modern multi-media society smart phones and social media sites became the "Time Eating Machine", a thing that made reading take a back seat.

Finally, having a social media account, like those on Snapchat or YouTube or even Instagram, also revealed a significant statistical impact on the general attitude towards reading and with the recreational reading attitude sub-scale, but not with academic reading attitude sub-scale. Social media for young students and for teens in the current generation was mainly used for browsing and downloading rather than for reading and educational purpose (Alqashan, 2017).

Policy makers should pay attention to the findings of this study. No one can deny the importance of mass-media technology in simplifying and modifying our lives. However, as Turkyilmaz (2014) noted that although the main aim of mass media technologies is to make people access information as fast as possible and share it at similar settings, children and teenagers preferred to use them to follow people or play computer games. Meanwhile, when young people are browsing on the internet, or playing games they are using and interacting in English language, that demonstrate English reading poses no threat to learning Arabic or to the national integration and development of Kuwait. On the contrary, using social media and smart devices can improve fluency in reading and speaking English that will make Kuwaiti students future ready in a competitive and increasingly globalizing world where they cope with their international peers.

In short, we should create and promote a community of lifelong readers in our schools, we need to create a school-wide culture; it will not simply happen by itself. This will need a multi-pronged strategy. Teachers should set aside time for independent reading in the curriculum, setting 15 minutes a day in the EFL schedule or self-independent reading. It is also advised to create a "Caught reading" program that features Teachers as Readers, who can initiate and lead a school-wide reading culture. Teachers should be supported building high-quality classroom libraries to help young learners have daily access to online and different types of authors, 
genres and text types. For instance, they can create a Twitter hashtag for sharing books, or school-wide \# hashtags for book readings and interactive reading clubs for sharing reading sites to parents and students. Such activities can build a school and create a community reading culture that will foster lifelong readers. Simultaneously, that will rebuild the logo which says that Kuwait belong to the nation that is obligated to read as the first verse in the Quran says "Read".

\section{References}

Al darwish, S., \& Akbar, R. (2013). EFL reading motivations: Evidence from Kuwait. Journal of Education and practice, 4(28), 203-211.

Al-edwani, A. (2005). Factors contributing to student's language learning difficulties in the college of Basic Education in Kuwait. Unpublished PhD thesis, University of Newcastle upon Tyne. UK.

Alqashan, H. (2017). Protecting young generation from Cyphers. Paper presented at Kuwait International conference "Protecting young generations from the negative influence of social media" Kuwait Ministry of Interior, Kuwait. March, 2107.

Abu-Rabia, S. (1995). Attitudes and Cultural Background and Their Relationship to English in a Multicultural Social Context: the case of male and female Arab immigrants in Canada. An international Journal of Experimental Educational Psychology, 15(3), 323-336. https://doi.org/10.1080/0144341950150307

Alexander, J. E., \& Filler, R. C. (1976). Attitudes and reading. Newark, DE: International Reading Association.

Artol, T., \& Llorente, S., Cratacos, G., \& Barraca, J. (2013). Differences in Boys and Girls attitudes toward reading: a comparison between Single sex and Coeducational schools. Paper presented at the Portugal EASSE Conference.

Azlina, M. S., \& Zaizati, Z. (2011). Relating Adolescents Second Language Reading Attitudes, Self Efficacy for Reading and Reading Ability in a Non-Supportive ESL Setting. The Reading Matrix, 11(3), 243-254.

Baleghizadeh, S., \& Oladrostam, E. (2010). The effect of mobile assisted language learning (MALL) on grammatical accuracy of EFL students. MEXTESOL Journal, 34, 1-10.

Baker, L., \& Wigfield, A. (1999) Dimensions of children's motivation for reading and their relations to reading activity and reading achievement. Reading Research Quarterly, 34, 452-477. https://doi.org/10.1598/RRQ.34.4.4

Beentjes, J. W., Coolstra, C. M., Marseille, N., \& Vander Voot, T. H. (2001). Children's Use of Different Media: How Long for and Why? In S. Livingstone, \& M. Bovill (Eds.), Children and Their Changing Media Environment: a European Comparative Study (pp. 85-111). Mahwah, NJ: LEA.

Black, L, A. (2006). Attitudes to Reading: An Investigation Across the Primary Years. A master thesis: Australian Catholic University McAuley Campus: AUSTRALIA.

Braden, J. M. (2012). Impacting Attitude Towards Reading in the Second-Grade Classroom: A Reading Role Model Intervention. A master Thesis. Wichita State University.

Brant M. (2003). Log on and learn. Newsweek, 52-55.

Butler, Y. G. (2007). Children's reading attitudes in L1 and FL. Academic Exchange Quarterly, 93-110.

Byro, C. C. (2000). A study of the relationship between reading attitude and gender in fourth grade children. Theses and Dissertations.

Chaudhry, A. S. (2014). Student response to e-books: study of attitude toward reading among elementary school children in Kuwait. The Electronic Library, 32(4), 458-472. https://doi.org/10.1108/EL-04-2012-0041

Clark, S., Jones, C. D., Reutzel, R. D., \& Anderson, L. (2013). An Examination of the Influences of a Teacher Preparation Program on Beginning Teachers' Reading Instruction. Literacy Research and instruction, 52(2), 87-105. https://doi.org/10.1080/19388071.2012.754520

Cook, R. B. (2012). Academic Reading Attitudes and Performance as a Function of Gender (Un published Doctoral dissertation). Auburn University, (pp. 1-95). Auburn, Alabama: Auburn University.

Comas-Quinn, A., Mardomingo, R., \& Valentine, C. (2009). Mobile blogs in language learning: from the most of informal and situated learning opportunities. RECALL, 21, 96-112. https://doi.org/10.1017/S0958344009000032

Deck, D., \& Barnette, J. J. (1976). Measuring attitudes toward reading in large-scale assessment. Paper 
presented at the Annual meeting of the American Educational Research Association, San Francisco.

Demirer, V., ÃintasYildiz, D., \& Sunbul, A. M. (2011). The Relationship between Primary School Students' Computer Internet Usage and Reading Habits: Sample of Kenya. Elementary Education Online, 10(3), 1-9.

Eccles, J. S., \& Wigfield, A. (2002). Motivational belief, values, and goals. Annual Review of Psychology, 53(1), 109-132. https://doi.org/10.1146/annurev.psych.53.100901.135153

Ehrenreich, B. (2011). The Death of the Book. LA Review of Books, Los Angeles.

Fender, M. (2008). Arabic literacy development and cross-linguistic effects. In K. Koda, \& A. Zehler (Eds.), Learning to read across languages (pp. 101-124). New York. Routeldge.

Gallagher-Brett, A. (2006). Hard Going but Worth it; a Snapshot of Attitudes to Reading Among Languages Undergraduates (pp. 1-39, Rep.). Highfield, Southampton: University of Southampton.

Goodwyn, A. (2011). Reading is now "cool": a study of English teachers' perspectives on e-reading devices as a challenge and an opportunity. Educational Review, 66(3), 263-275. https://doi.org/10.1080/00131911.2013.768960

Gonzalez, P. (2012). La asombrosa de Kevin Systrom, funador de Instagram. In J. Villafuerte, \& A. Romero (2017) Learners' attitude toward foreign language practice on social network. Sites. Journal of Education and learning, 6(4), 145-158.

Griva, E., Alevriadou, A., \& Semoglou, K. (2012). Reading Preferences and Strategies Employed by Primary School Students: Gender, Socio-Cognitive and Citizenship Issues. University of Western Macedonia: International Education Studies, 5(2).

Greenfield, J. (2012). For reading and learning, kids prefer e-books to print books.

Junaid, J. (2015). Gender Differences in Reading Achievements. Perceived gender differences in reading achievement and motivation. A master Thesis at Ontario Institute for Studies in Education of the University of Toronto.

Kennedy, A. (2006). Examining Gender and Fourth Graders Reading Habits and Attitudes in PIRLS 2001 and 2006. TIMSS \& PIRLS International Study Center, Boston College, Chestnut Hill, MA, USA.

Kondo, M., Ishikawa, Y., Sakamoto, K., Shimomoura, H., \& Wade, N. (2012). Mobile assisted language learning in university EFL courses in Japan: developing attitude and skills for self-regulated learning. RECALL, 24, 169-187. https://doi.org/10.1017/S0958344012000055

Kirschner, P. (2015). Facebook as learning platform: Argumentation superhighway or dead-end street? Computer in Human Behavior, 53, 621-625. https://doi.org/10.1016/j.chb.2015.03.011

Larson, L.C. (2009) E- reading and e-responding: new tools for the next generation of readers. Journal of Adolescent and Adult Literacy, 53(3), 255-258. https://doi.org/10.1598/JAAL.53.3.7

Larson, L. C. (2010). Digital readers: the next chapter in e-book reading and response. The Reading teacher, 64(1), 15-22. https://doi.org/10.1598/RT.64.1.2

Loan, F. A. (2009). Impact of New Technology on Reading Habits: A Glimpse on the World Literature, presented at National Seminar Role of School Libraries in Quality Education, New Delhi, 10-11 2009. New Delhi, India: Division of Library, Documentation and Information.

Logan, S., \& Johnston, R. (2009). Gender differences in reading ability and attitudes: examining where these differences lie. Journal of Research in Reading, 32(2), 199-214. https://doi.org/10.1111/j.1467-9817.2008.01389.x

Martinez, R. S., Aricak, O. T., \& Jewell, J. (2008). Influence of reading attitude on reading achievement. Atest of the temporal-interaction model. Psychology in the schools, 45, 1010-1022. https://doi.org/10.1002/pits.20348

Mckenna, M. C., \& Kear, D. J. (1990). Measuring Attitude Toward Reading: A New Tool for Teachers. The Reading Teacher, 43(8), 626-639. https://doi.org/10.1598/RT.43.8.3

Mckenna, M. C., Kear, D. J., \& Ellsworth, R. A. (1995). Children's Attitudes toward Reading: A National Survey. Reading Research Quarterly, 30(4), 934-955. https://doi.org/10.2307/748205

Merisuo-Storm, T. (2006). Girls and Boys Like to Read and Write Different Texts. Scandinavian Journal of Educational Research, 50(2), 111-125. https://doi.org/10.1080/00313830600576039

Mohd-Asraf, R., \& Abdullah, H. (2016). Elementary Schoolers' Attitudes toward Reading in English: How Boys 
Feel Relative to Girls. English Language Teaching, 9(6), 134-140. https://doi.org/10.5539/elt.v9n6p134

Mullis, I. V. S., Martin, M. O., Kennedy, A. M., \& Foy, P. (2007). PIRS 2006 International Report. IES 'S Progress in International Reading Literacy Study in Primary school in 40 Countries, TIMSS\& PIRLS International Study Center, Boston College, Chestnut Hill, MA.

Pachler, N., Cook, J., \& Bradley, C. (2009). I don't really see it: whiter case -based approaches to understand off-site and on campus mobile learning? In G. Vavoula, N. Pachler, \& A. Kukulska-Hulme (Eds.), Researching mobile learning (pp.77-96). Bern: Peter lang.

Sahbaz, N. K. (2012). Evaluation of reading attitudes of 8th grade students in primary education according to various variables. Educational Research and Reviews, 7(26), 571-576.

Salinas, J. (2001). EL rol del profesor en la transicion de le ensenanza presencial al aprendizaje on line.

Shannon, J. (2003). Getting Gulf students to enjoy reading. Perspectives, 11(1), 21-24.

Schwartz, W. (2002). Helping Underachieving Boys Read Well and Often. ERIC Digest, 1-9. Retrieved July 29, 2017, from http://files.eric.ed.gov/ fulltext/ED467687.pdf

Shehu, N., \& Shehu, A. (2014). Challenges of Social Networking on Students Reading Habit in Ahmadu Bello University, Zaria. Research on Humanities and Social Sciences, 4(19), 34-39.

Smith, M. C. (1990). A longitudinal investigation of reading attitude development from childhood to adulthood. The Journal of Educational Research, 83, 215-219. https://doi.org/10.1080/00220671.1990.10885958

Stanfield, G. M. (2008). Incentives: The effects on reading attitude and reading behaviors of Third- grade students. The Corinthian, 9, 99-116.

Stevens, S. (2011). Entering Book world: How to Help Both Boys and Girls in Class Read Aloud. Teacher as Leader, EDU 600, pp. 1-9.

Tan, V., \& Majid, S. (2008). Understanding the Reading Habits of Children in Singapore. Journal of Educational Media \& Library Sciences, 45(2), 187-198.

Turkyilmaz, M. (2014). The effect of Mass Media on Attitude Toward Reading. Pensee Journal, 76(5), 295-304.

Villafuerte, J., \& Romero, A. (2017). Learners' Attitude toward foreign language practice on social network sites. Journal of Education and learning, 6(4), 145-158. https://doi.org/10.5539/jel.v6n4p145

Wade, Q. D. (2012). The Relationship between Reading Attitude, Self-Efficacy, Motivation, and the Reading Achievement of Fifth Grade African-American Males (Unpublished master's thesis). Howard University. Retrieved from https://search.proquest.com/ docview/1027145572

Wang, X. (2000). Children's attitudes toward reading and their literacy development. Journal of Instructional Psychology, 27, 120-125.

Watson, A., Kehler, M., \& Martino, W. (2010). The Problem of Boys Literacy Underachievement: Raising Some Questions. Journal of Adolescent \& Adult Literacy, 53(5), 356-361. https://doi.org/10.1598/JAAL.53.5.1

World Bank Report. (2016). World development report, Digital Dividends. Retrieved July 13, 2017, from http://www.worldbank.org/en/publication/wdr2016

\section{Copyrights}

Copyright for this article is retained by the author(s), with first publication rights granted to the journal.

This is an open-access article distributed under the terms and conditions of the Creative Commons Attribution license (http://creativecommons.org/licenses/by/4.0/). 